\title{
Effects of natural and anthropogenic gradients on native and exotic winter annuals in a southern California Desert
}

\author{
Leela E. Rao $\cdot$ Robert J. Steers $\cdot$ Edith B. Allen
}

Received: 12 May 2010/Accepted: 16 December 2010/Published online: 4 January 2011

(C) The Author(s) 2010. This article is published with open access at Springerlink.com

\begin{abstract}
Native annual plant species constitute a large proportion of the plant diversity found in arid vegetation types within the southwestern United States; yet, little is known about controls on diversity patterns along natural and anthropogenic gradients. In this study we evaluated native species richness and exotic species cover across overlapping gradients of precipitation, wind, and $\mathrm{N}$ deposition in the Colorado Desert of southern California. Factors allowing native diversity to persist under high $\mathrm{N}$ deposition and high wind were also evaluated in a second, focused study
\end{abstract}

Electronic supplementary material The online version of this article (doi:10.1007/s11258-010-9888-5) contains supplementary material, which is available to authorized users.

L. E. Rao · E. B. Allen

Center for Conservation Biology, University

of California, Riverside, CA 92521, USA

R. J. Steers · E. B. Allen

Department of Botany and Plant Sciences, University

of California, Riverside, CA 92521, USA

R. J. Steers

San Francisco Area Network, Inventory and Monitoring Program, US National Park Service, Fort Cronkhite,

Sausalito, CA 94965, USA

L. E. Rao $(\square)$

CA Air Resources Board, 9480 Telstar Ave. Suite 4, El Monte, CA 91731, USA

e-mail: 1rao@arb.ca.gov at one end of the gradient. We found that gradients in precipitation, nitrogen deposition, and wind were the most important factors to native richness and exotic species cover across the landscape, while local heterogeneity in bare ground influenced richness and cover at the high deposition/windy, or highdisturbance, end of the gradient. Patterns of native diversity were evaluated across the gradients using non-metric multidimensional scaling, which showed diversity was split into two axes: one strongly correlated to precipitation and the other strongly correlated with disturbance factors. The disturbance factors were also positively associated with exotic grass and forb cover. In total, these results indicate that large-scale patterns in disturbance and exotic species cover negatively affect native annual plant species diversity but native species can also persist due to local heterogeneity.

Keywords Invasive - Native diversity - Disturbance Species change $\cdot$ Creosote bush scrub $\cdot$ Arid

\section{Introduction}

Environmental gradients have been shown to control native and exotic species diversity (e.g., Motzkin et al. 1999; Pyke et al. 2001; Stohlgren et al. 2005). However, the control of environmental gradients on diversity and abundance of exotic species may be secondary to environmental disturbances that create 
favorable conditions for invasion (Hobbs and Huenneke 1992; Davis et al. 2000). The Colorado Desert in southern California is an ideal location for examining the effects of environmental gradients and disturbance on native species diversity and exotic species invasion because this region has overlapping gradients of precipitation, nitrogen $(\mathrm{N})$ deposition, and wind, all of which may impact diversity and invasion processes. In addition, the primary component of plant diversity in this region is the native winter annual forbs, which are under pressure from the invasion of several exotic annual grasses and forbs (Barrows et al. 2009; Steers and Allen 2010).

Precipitation is the primary limiting factor for plant growth in arid environments (Noy-Meir 1973), and the timing and amount of precipitation can significantly impact the diversity and richness of the annual community in a given year (Beatley 1966; Bowers 2005). Precipitation also interacts with soil properties to affect availability of both water and nutrients to plants (Austin et al. 2004). In the Colorado Desert, most precipitation occurs in the winter months, with the greatest germination of winter annuals occurring after the first major rain storm of at least $25 \mathrm{~mm}$ (Beatley 1966). In this region, precipitation varies widely from $186 \mathrm{~mm}$ of winter precipitation at the western-most end of the Coachella Valley to $90 \mathrm{~mm}$ on the eastern end of the gradient (Table 1).

In addition to the west-to-east gradient in precipitation, there is a west-to-east gradient in $\mathrm{N}$ deposition (Rao et al. 2009; Fenn et al. 2010). Nitrogen is considered the secondary limiting factor to plant production in arid systems (Hooper and Johnson 1999), and several exotic grasses and forbs found in this region are promoted by increased levels of soil $\mathrm{N}$ (DeFalco et al. 2003). Native desert annuals also respond positively to increased soil $\mathrm{N}$ (DeFalco et al. 2003; Salo et al. 2005), but when native and exotic annuals are grown together, the exotic species can have greater responses to increased $\mathrm{N}$ compared to the native annuals (Salo et al. 2005). This suggests that over time native annuals may be outcompeted by exotic annuals in areas with high $\mathrm{N}$ deposition, resulting in local species extirpation and homogenization of the native flora. However, field studies on the effect of increased $\mathrm{N}$ availability on native and exotic annuals indicate that relative performance by the two plant groups may be dependent on precipitation amounts (Brooks 2003; Rao and Allen 2010) and further investigation is needed.

The third large-scale gradient in this region is one of wind. Although wind is considered a physical environmental property, it can also be considered a form of physical disturbance. In the Coachella Valley, wind speed ranges from $>8.5 \mathrm{~m} \mathrm{~s}^{-1}$ in the west to $<4.5 \mathrm{~m} \mathrm{~s}^{-1}$ in the east (CEC 2007), although wind speeds may vary over small distances due to local topography (Tieleman 1992). Wind is the dominant force in maintaining the dune systems that are present in the region (Sharp 1964). In addition, in coastal dune systems wind has been shown to facilitate exotic species invasion (Lortie and Cushman 2007), although to our knowledge the influence of wind on exotic species invasion has never been evaluated in arid systems.

Table 1 Seasonal precipitation from the summer 2003 through winter 2008 plus average values and long-term, historical averages

\begin{tabular}{|c|c|c|c|c|c|c|c|}
\hline & \multicolumn{7}{|c|}{ May through September precipitation $(\mathrm{cm})$} \\
\hline & 2003 & 2004 & 2005 & 2006 & 2007 & Average & Long-term average \\
\hline Palm Springs & 1.3 & 0.2 & 0.9 & 0.5 & 0.1 & 0.6 & $2.3^{\mathrm{a}}$ \\
\hline \multirow[t]{3}{*}{ Hayfield } & 12.7 & 0.8 & 7.7 & 1.1 & 7.5 & 6 & $3.3^{\mathrm{b}}$ \\
\hline & \multicolumn{7}{|c|}{ October through April precipitation $(\mathrm{cm})$} \\
\hline & $2003-2004$ & 2004-2005 & 2005-2006 & $2006-2007$ & 2007-2008 & Average & Long-term average \\
\hline Palm Springs & 8.7 & 32.4 & 5.7 & 2 & 10.6 & 11.9 & $11.5^{\mathrm{a}}$ \\
\hline Hayfield & 10.5 & 35.4 & 2.7 & 2.5 & 7.2 & 11.7 & $7^{b}$ \\
\hline
\end{tabular}

Data were obtained from National Climatic Data Center weather stations (WRCC 2010)

a Average based on data from March 1, 1906 to July 31, 2009

b Average based on data from July 1, 1933 to August 31, 2009 
The purpose of this study is to examine the effects of these three large-scale gradients on native annual richness and diversity, as well as on exotic annual cover. As these gradients are overlapping to some degree, several statistical methods were used in an attempt to disentangle these effects. In addition, a second study focusing on the western end of the gradient with high winter precipitation $(186 \mathrm{~mm})$, high $\mathrm{N}$ deposition $\left(10.6 \mathrm{~kg} \mathrm{ha}^{-1}\right.$ year $^{-1}$ ), high wind impacts $\left(>8.5 \mathrm{~m} \mathrm{~s}^{-1}\right)$, and high levels of exotic species invasion was conducted to better understand the local-scale factors that maintain native annual richness in the face of numerous environmental, biotic, and abiotic pressures.

\section{Methods}

Study location

All data were collected in the Colorado Desert of Riverside County, California in Larrea tridentatadominated creosote bush scrub (Sawyer et al. 2009). The high-disturbance study area was on the western edge of Coachella Valley and was approximately $12 \mathrm{~km}$ west to east and $13 \mathrm{~km}$ north to south (Fig. 1). In the high-disturbance area, the average winter precipitation (November to April rain from 1971 to 2001) is $25.1 \mathrm{~cm} \mathrm{year}^{-1}$ (PRISM 2006), the estimated $2002 \mathrm{~N}$ deposition load is $14.8 \mathrm{~kg}$ ha year $^{-1}$
(Tonnesen et al. 2007; Fenn et al. 2010), and all study sites were chosen to have similar soil types (gravelly alluvium derived from granite) and slope $\left(1-5^{\circ}\right)$ (NRCS 2006).

The landscape gradient study spanned an $85 \mathrm{~km}$ longitudinal transect starting near the western-most extent of creosote bush scrub in the Banning Pass near Cabazon and ending at Pinto Basin in Joshua Tree National Park (Fig. 1). The average winter precipitation ranges from 18.6 to $7.9 \mathrm{~cm}$ (PRISM 2006) and average annual $\mathrm{N}$ deposition ranges from 14.7 to $2.4 \mathrm{~kg} \mathrm{ha}^{-1}$ year $^{-1}$ (Tonnesen et al. 2007) from west to east along the transect. The parent material found along the transect was granite, with varying soil characteristics. In both the high-disturbance and landscape study areas, washes and sand dune habitats were avoided because of the highly dynamic and invasion prone substrate they are known for (Barrows et al. 2009; Sawyer et al. 2009), which would have confounded our study.

Summer precipitation is typically scarce within the high-disturbance study area but increases eastward. Average summer precipitation from 2003 to 2007 was $6 \mathrm{~cm}$ at Hayfield, near the eastern end of the gradient but only $0.6 \mathrm{~cm}$ at Palm Springs, near the western end (Table 1). Long-term records indicate that winter precipitation is greater in the western portion of the landscape scale study area and decreases toward the east (WRCC 2010). However, from the 2003-2004 to the 2007-2008 winter season,
Fig. 1 Locations of plots used in the high-disturbance (labels $A-F$ ) and landscape gradient (labels 1-7) studies. Major cities, highways, and county line noted for reference

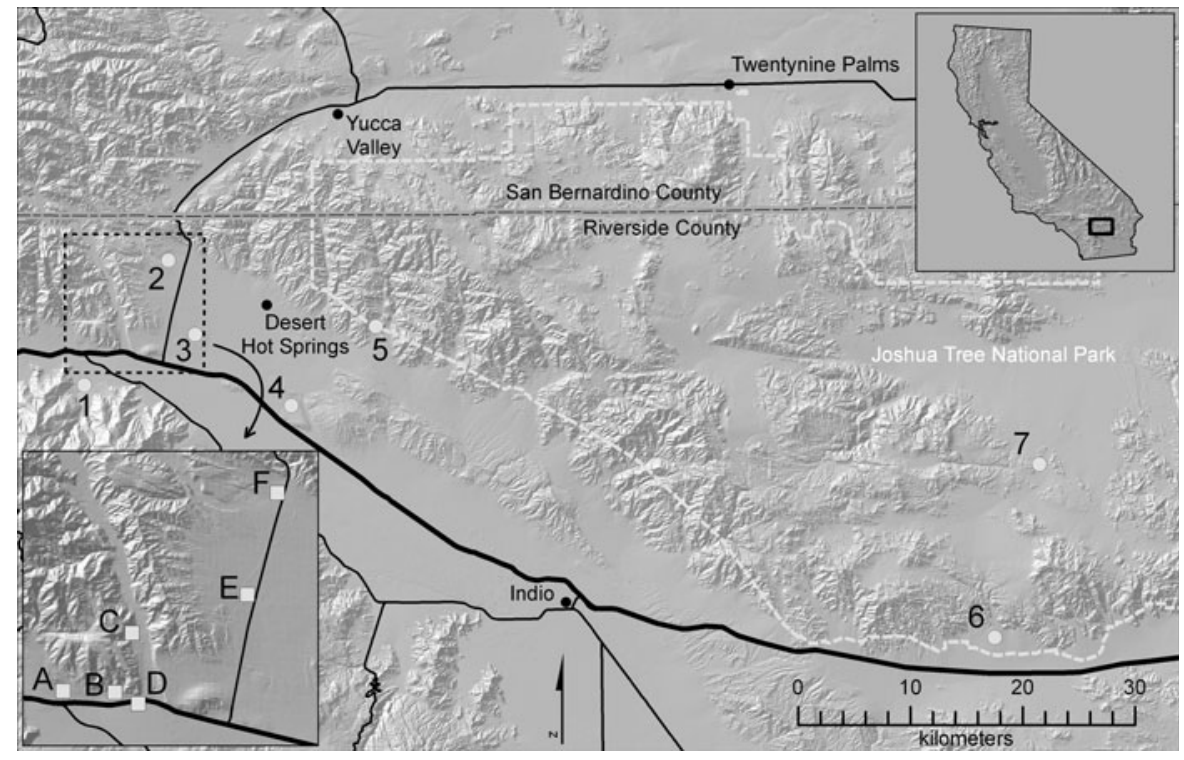


precipitations at Palm Springs and Hayfield were very similar (Table 1).

\section{High-disturbance area}

Six study sites were chosen with similar vegetation and soil type in areas with no visible evidence of livestock grazing or fire history based on an aerial photo series dating back to 1949 (Steers 2008). At each study site 6 sampling units were implemented using a stratified random design. Sampling units consisted of one $14.6 \mathrm{~m}$ diameter circular modifiedNational Weed Management Association (modNAWMA) plot (Stohlgren et al. 2003). In August and September of 2006, four $2.5 \mathrm{~cm}$ diameter by $5 \mathrm{~cm}$ deep soil cores per mod-NAWMA plot were taken and pooled into one composite sample per plot for nutrient analysis. The four samples were analyzed for total carbon (C), total nitrogen (N), $\mathrm{NH}_{4}{ }^{+}$, and $\mathrm{NO}_{3}{ }^{-}$. In addition, one $5 \mathrm{~cm}$ diameter core was taken to a $5 \mathrm{~cm}$ depth at the center of the plot for bulk density, coarse fraction $(>2 \mathrm{~mm})$, and soil texture determination. Nutrient and soil texture analyses were conducted by the UC Davis Analytical Laboratory (http://groups.ucanr.org/danranlab).

In the winter of 2006-2007, insufficient rainfall prevented the germination of annual plants at the study sites and no vegetation measurements were taken. In the following wet season of 2007-2008, precipitation was about average (Table 1) and vegetation was sampled throughout March 2008 during peak flowering. Percent cover by species, bare ground, and large rock $(>75 \mathrm{~mm})$ were measured in three $1 \mathrm{~m} \times 1 \mathrm{~m}$ quadrats per mod-NAWMA plot, and species richness values were assessed of the entire mod-NAWMA plot $\left(168.3 \mathrm{~m}^{2}\right)$. Although the vegetation and soil parameters were collected in different years, it was considered appropriate to use the prior year's soil data in the statistical analyses since multiyear soil collections from the same region show that although there are yearto-year fluctuations in extractable soil nutrients, values of total $\mathrm{C}$ and $\mathrm{N}$ and physical parameters are less variable, and the relative difference between sites is consistent (L. Rao, unpublished data).

\section{Landscape gradient}

At each study site, three 1 -ha $(100 \mathrm{~m} \times 100 \mathrm{~m})$ study plots were placed using a stratified random sampling design in creosote bush scrub, and all sampling was conducted at peak flowering in March of 2005. Within each 1-ha plot, five 50-m transects were evenly placed with all five transects $15 \mathrm{~m}$ apart. Along each transect, a $0.5 \mathrm{~m} \times 1 \mathrm{~m}$ quadrat was placed every $10 \mathrm{~m}$ resulting in a total of five quadrats per line, and percent cover was measured by species in each quadrat (25 per 1-ha plot, 75 per site). Species richness was also recorded within each 1-ha study plot by combing through the entire area and recording each species encountered.

In 2005 when vegetation was sampled, soil samples were taken at the midpoint of transects 1 , 3 , and 5 using five $2.5 \mathrm{~cm}$ diameter by $5 \mathrm{~cm}$ deep cores per sample point. Soil cores were taken to a depth of $5 \mathrm{~cm}$, pooled, and analyzed for total $\mathrm{C}$, total $\mathrm{N}, \mathrm{NH}_{4}{ }^{+}$, and $\mathrm{NO}_{3}{ }^{-}$by the UC Davis Analytical Laboratory. In the summer of 2007, we conducted dry season soil sampling for $\mathrm{NH}_{4}{ }^{+}$and $\mathrm{NO}_{3}{ }^{-}$since inorganic $\mathrm{N}$ accumulates at the soil surface during the summer and provides a good proxy for $\mathrm{N}$ deposition (Padgett et al. 1999; Rao et al. 2009). Also during the dry season, a $5 \mathrm{~cm}$ diameter soil core was taken at each soil sample point for bulk density, soil texture, and coarse fraction determination. Lastly, percent cover of rock in different size classes was measured using a $1 \mathrm{~m} \times 0.5 \mathrm{~m}$ gridded quadrat at the soil sample collection sites.

For each site, average winter precipitation, annual $\mathrm{N}$ deposition, and windiness were estimated. An index of wind disturbance, or windiness, was determined based on shrub measurements taken at each of the study sites. Within each 1-ha plot, the nearest mature L. tridentata shrub from the $0 \mathrm{~m}$ (start) and $50 \mathrm{~m}$ (end) points on odd numbered line transects were measured, resulting in 6 shrubs per plot. For each shrub, the linear direction of greatest unevenness in canopy width between its two halves (windward and leeward sides) was determined using the base of the shrub stem as the axis point (Wade and Hewson 1979), and the corresponding compass direction was recorded. Along this line of greatest unevenness in shrub width, the lengths of the canopy halves on each side of the shrub stem (i.e., the windward and leeward halves of the canopy) were measured. Then, the ratio of windward to leeward canopy length was determined. An index of windiness was calculated per study plot (using all six shrubs) by multiplying the standard error of the 
compass direction (magnetic degrees) of greatest canopy unevenness by the average ratio of windward to leeward canopy length. Plots with low standard error and low ratios had the most severe windflagging and hence were indicative of the windiest or most wind-disturbed sites.

\section{Statistical analyses}

\section{High-disturbance area}

Correlations of the edaphic (soil-based) parameters revealed significant collinearity among certain variables (Online Resource 1A). Therefore, the best-fit uncorrelated model based on the lowest $\mathrm{AIC}_{\mathrm{c}}$ (Akaike's Information Criterion) score was chosen for multiple regression. The most parsimonious reduced-rank model for both native annual richness and exotic annual cover used bare ground and total $\mathrm{C}$ as the independent variables. A study of the relationships within the set of edaphic parameters was also made using principle component analysis, but no useful improvements in interpretation were found.

\section{Landscape gradient}

For the landscape gradient analysis, correlations of the edaphic, climate, and disturbance variables revealed significant collinearity (Online Resource 1B). Therefore, the best-fit uncorrelated models for native richness and exotic cover were determined based on the models with the lowest $\mathrm{AIC}_{\mathrm{c}}$ scores. The most parsimonious uncorrelated model for native annual richness used percent cover of 5-75 $\mathrm{mm}$ size-class rocks and $\mathrm{N}$ deposition as the independent variables; for exotic annual cover the best-fit model used percent bare ground and wind as the independent variables. As with the edaphic variables at the local scale, principle component analysis was conducted for the independent variables at the landscape scale, but no useful improvements in interpretation were found.

Patterns of native diversity across the landscape were analyzed using non-metric multidimensional scaling (NMDS) conducted on the native presenceabsence data and a Sørensen index of dissimilarity. Ordinations were performed in one and two dimensions, but the one-dimensional solution did not capture a sufficient amount of variation compared to the two-dimensional solution (62\% vs. $87 \%)$ and so the two-dimensional solution was used in subsequent analyses.

To account for the effect of geographic distance on native and exotic species correlations with the environment, simple and partial matrix correlations (Mantel tests) were conducted using dissimilarity matrices. Correlations were conducted between a species dissimilarity matrix (native presence-absence, exotic grass cover, or exotic forb cover) and the environmental or distance matrix alone (simple) or with one controlling for the other (partial). Native species presence-absence data were converted into a dissimilarity matrix using the Sørensen index. Precipitation and $\mathrm{N}$ deposition were combined into one environmental matrix as these were the most significant correlates with the two NMDS axes. The matrices for exotic species cover, environmental parameters, and distance were all standardized and converted to dissimilarity matrices using Euclidean distances. Exotic species presence-absence was not evaluated due to the low variation in exotic species diversity along the gradient in comparison to percent cover.

The extent of homogenization of the native community by exotic species was calculated as: $H=$ similarity(native + exotic) - similarity(native) (Qian and Ricklefs 2006), based on the Jaccard index of similarity. Homogenization $(H)$ was then compared to the geographical distance between two sites using linear regression.

For landscape gradient analyses, distance matrices, matrix standardizations, and NMDS were conducted using PC ORD (McCune and Medford 1999). Mantel tests were conducted using ZT (Bonnet and Peer 2002). JMP 8.0 (SAS Institute, Inc., 2009) was used to conduct all other correlations, linear regressions, principle components analyses, and multiple linear regressions for both the high-disturbance and landscape gradient studies. In all cases, significance was set using an alpha level of 0.05 and data were transformed as necessary to satisfy the requirements of the testing conducted.

There are several inferential caveats pertaining to the landscape scale analyses to note: (1) The correlations between species distributions and environmental factors do not necessarily indicate causation or identify mechanisms underlying the correlations. (2) The plots are not spatially independent and many of the environmental variables and species distributions are presumably spatially patterned. We 
attempted to address this fact by explicitly examining geographical distance in the partial Mantel tests, but the spatial correlation makes it difficult to identify individual factors that control species distributions. (3) There is variation in the precision of the quantification of variables; some variables are available only for a site (e.g., precipitation, $\mathrm{N}$ deposition) while others are plot averages (e.g., edaphic variables). (4) Sites along the landscape gradients of $\mathrm{N}$ deposition and precipitation were not equally spaced and were biased toward the wet, high $\mathrm{N}$ deposition end of the gradient; however, a range of $\mathrm{N}$ deposition from 2.4 to $14.8 \mathrm{~kg} \mathrm{ha}^{-1}$ year $^{-1}$ and precipitation from 79 to $186 \mathrm{~mm}$ were sampled. Despite these limitations, we believe that the use of multiple complementary statistical analyses allows for some conclusions to be made regarding the patterning of species in this region.

\section{Results}

Factors influencing native diversity and exotic cover

Average soil characteristics and a list of the species found across the high-disturbance study area and landscape gradient are provided in the electronic supplemental materials (Online Resources 2A and $2 \mathrm{~B}$, respectively). For the high-disturbance area, the environmental variables used in the reduced-rank model to analyze native richness and exotic cover were total \% bare ground and total soil $\mathrm{C}$, which could be thought of as openness/sandiness and fertility, respectively, based on their correlations with the other edaphic variables. Sixty percent of the variance in native richness was explained by the model; total $\mathrm{C}$ was negatively related to native richness while bare ground was positively related to native richness (Table 2 ). The exotic cover model had a better fit $\left(R^{2}=0.77\right)$, and the directions of the effects of total $\mathrm{C}$ and bare ground were opposite those from the model for native richness (Table 2).

For the landscape gradient, different reduced-rank models were used to describe native richness and exotic cover. Seventy-three percent of the variance in native richness was explained by $\mathrm{N}$ deposition $(P<0.0001$, positively related) and rock cover ( $P=0.01$, negatively related) (Table 2 ). The model for exotic annuals explained $73 \%$ of the variance in cover using the independent variables of $\%$ bare ground $(P=0.005$, negatively related) and wind $(P<0.0001$, negatively related to index). As the wind index is a negative index, the relationship between exotic annual cover and windiness is positive.

Table 2 Multiple linear regression results on native species richness and exotic annual cover for the high-disturbance and landscape gradient datasets

\begin{tabular}{|c|c|c|c|c|c|}
\hline \multirow[t]{2}{*}{ High-disturbance area analysis } & \multicolumn{2}{|c|}{ Native richness $\left(R^{2}=0.60, n=36\right)$} & \multicolumn{3}{|c|}{ Exotic grass + forb cover $\left(R^{2}=0.77, n=36\right)$} \\
\hline & Estimate & Prob $>|t|$ & & Estimate & Prob $>|t|$ \\
\hline Intercept & 2.88 & 0.0006 & Intercept & 0.38 & 0.026 \\
\hline Total C $\left(\mathrm{g} \mathrm{m}^{-2}\right)$ & -0.28 & 0.0009 & Total C $\left(\mathrm{g} \mathrm{m}^{-2}\right)$ & 0.07 & $<0.0001$ \\
\hline$\%$ Cover of bare ground & 0.48 & $<0.0001$ & $\%$ Cover of bare ground & -0.17 & $<0.0001$ \\
\hline \multirow[t]{2}{*}{ Landscape gradients analysis } & \multicolumn{2}{|c|}{ Native richness $\left(R^{2}=0.73, n=21\right)$} & \multicolumn{3}{|c|}{ Exotic grass + forb cover $\left(R^{2}=0.73, n=21\right)$} \\
\hline & Estimate & Prob $>|t|$ & & Estimate & Prob $>|t|$ \\
\hline Intercept & 1.96 & $<0.0001$ & Intercept & 4.80 & $<0.0001$ \\
\hline $\mathrm{N}$ deposition $\left(\mathrm{kg} \mathrm{ha}^{-1}\right)$ & -0.48 & $<0.0001$ & $\%$ Cover of bare ground & -0.01 & 0.005 \\
\hline$\%$ Rock cover & -0.07 & 0.012 & Wind Index & -0.37 & $<0.0001$ \\
\hline
\end{tabular}

Regressions for the high-disturbance dataset were run against bare ground (correlated with soil texture) and total C (correlated with inorganic $\mathrm{N}$ and total $\mathrm{N}$ ). Bare ground is negatively correlated with the fertility measures, although these correlations are small and with the exception of inorganic $\mathrm{N}$, insignificant. Regressions for the landscape gradients dataset were run against modeled $\mathrm{N}$ deposition (correlated with inorganic soil $\mathrm{N}$, wind, and precipitation) and rock cover (correlated with precipitation) for native richness; bare ground (correlated with sand, total $\mathrm{N}$, and total $\mathrm{C}$ ) and wind index (correlated with $\mathrm{N}$ deposition, precipitation, and inorganic soil $\mathrm{N}$ ) were the best explanatory variables for the exotic cover model 
Bio-physical gradients and diversity

The NMDS analysis on native species presenceabsence data across the landscape gradients yielded a two-axis solution, with the first axis explaining $46 \%$ of the variance in diversity and the second axis explaining $41 \%$. The first axis was highly correlated $(r>0.70)$ with precipitation $(P<0.0001)$ and rock cover $(P=0.0001)$ (Fig. 2$)$. The remaining variables had correlations with axis 1 that were less than 0.60 . The second axis was highly correlated with $\mathrm{N}$ deposition $(P<0.0001)$ and inorganic $\mathrm{N}(P=$ $0.0005)$. This axis was also moderately correlated $(0.70>r>0.60)$ with exotic grass cover $(P=$ $0.001)$, wind $(P=0.0016)$, and exotic forb cover $(P=0.003)$.

Both NMDS axes were correlated with geographical distance (axis $1 r=-0.79$, axis $2 r=0.72$ ). Partial Mantel tests were conducted to quantify the effect of distance on diversity in relation to the natural and anthropogenic gradients. As precipitation and $\mathrm{N}$ deposition had the strongest correlations with axes 1 and 2, respectively ( $r=0.97$ and $r=-0.92$ ), these variables were chosen to represent the two large-scale gradients and were combined into one gradient matrix. A simple Mantel test indicated that distance was significantly correlated with the gradient matrix $(r=0.79, P=0.0001)$. Mantel tests on native diversity indicated that diversity was correlated with distance and the gradients when tested separately; when controlling for the effect of the gradients, distance was no longer significantly correlated with diversity (Table 3). Exotic forb cover was significantly correlated with the gradients only, although once controlling for distance, the correlation was no longer significant. Exotic grass cover was correlated with the gradients, but not distance, when examined separately. However, when controlling for the other matrix, both distance and the gradients were significantly correlated with grass cover. In total, these results indicate that geographical distance does not play a significant role in explaining native annual diversity or exotic forb cover in this region, although it is an important explanatory element for exotic grass cover.

Regression of the homogeneity index $(H)$ against distance indicated there was no evidence of native annual homogenization due to invasion across the gradient $\left(R^{2}=0.05\right)$. Homogeneity values were generally negative and close to zero
Fig. 2 Correlations of NMDS axes 1 and 2 to the environmental and disturbance variables. Environmental and disturbance variables abbreviated as follows: dist distance, rock \% cover of rocks, wind index of windiness, $T C$ total carbon, $T N$ total nitrogen, sand \% sand content in soil, EG\% cover of exotic grasses, $E F$ $\%$ cover of exotic forbs, $I N$ inorganic nitrogen, NDep modeled $\mathrm{N}$ deposition, and Precip average winter precipitation

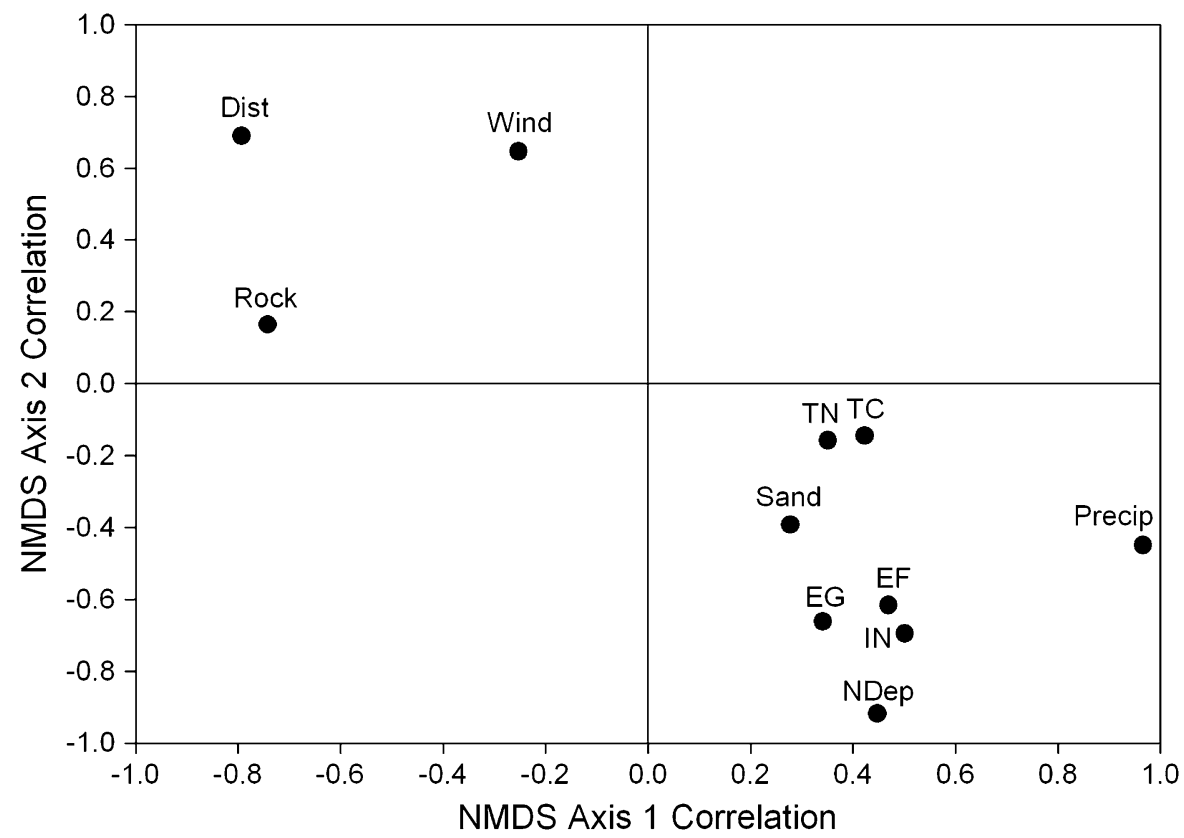


Table 3 Regular and partial Mantel test correlations between the species matrices, the environmental gradient matrix, and geographical distance

\begin{tabular}{lllrr}
\hline Matrix 1 & Matrix 2 & Matrix 3 & $r$ & $P$ value \\
\hline NA species & Environment & & 0.820 & 0.0001 \\
NA species & Distance & & 0.597 & 0.0001 \\
NA species & Environment & Distance & 0.709 & $<0.0001$ \\
NA species & Distance & Environment & -0.151 & 0.0720 \\
EF cover & Environment & & 0.161 & 0.0402 \\
EF cover & Distance & & 0.091 & 0.2005 \\
EF cover & Environment & Distance & 0.146 & 0.1527 \\
EF cover & Distance & Environment & -0.060 & 0.2206 \\
EG cover & Environment & & 0.439 & 0.0002 \\
EG cover & Distance & & 0.144 & 0.0586 \\
EG cover & Environment & Distance & 0.538 & 0.0001 \\
EG cover & Distance & Environment & -0.371 & 0.0002 \\
\hline
\end{tabular}

The native species presence-absence data were converted to a Sorensen dissimilarity matrix prior to testing. All other matrices were standardized and converted to dissimilarity matrices using Euclidean distance. Matrix 1 is the species matrix, Matrix 2 is the primary matrix (environmental matrix $=$ precipitation $+\mathrm{N}$ deposition; distance matrix $=$ distance between sites in $\mathrm{km}$ ), and Matrix 3 is the matrix that is factored out in the partial Mantel correlations

$N A$ species native annual presence-absence species data, $E F$ cover exotic forb percent cover data, EG cover exotic grass percent cover data

(mean $\pm \mathrm{SD}=-0.034 \pm 0.015$ ), with the largest $H$ values occurring between sites with the lowest Jaccard similarity values $(J<0.3)$.

\section{Discussion}

Factors influencing native diversity and exotic cover

In evaluating the factors controlling native richness and exotic annual cover across the landscape gradients, we found that the most influential parameters were related to disturbance. $\mathrm{N}$ deposition was the dominant explanatory variable for native richness, and wind disturbance was most strongly associated with exotic annual cover. As $\mathrm{N}$ deposition, wind, and precipitation are positively correlated, it was not possible to separate out the effects of these variables in the multiple regression. However, the regression showed that native richness was high in areas with low average precipitation, wind, and $\mathrm{N}$ deposition, while exotic grass and forb cover were reduced in these areas. In arid regions, total production is driven by precipitation (Noy-Meir 1973) but native diversity is often greater in areas with lower resource availability (Shmida and Whittaker 1981; Gutierrez et al. 1993; Pugnaire et al. 1996). These findings of higher diversity in resource poor areas coupled with the studies demonstrating the high-resource needs of the exotic grasses in our region (DeFalco et al. 2003; Salo et al. 2005) support our findings of higher native diversity on the drier, $\mathrm{N}$-poor end of the gradient and higher exotic species cover on the wetter, N-rich end of the gradient. Exotic species have been shown to directly compete with native species in this region (Barrows et al. 2009; Steers and Allen 2010). Thus, it may be that exotic annuals are exerting pressure on the native annuals at the more productive, but more disturbed end of the gradient. Such pressure may also be occurring on the resource poor end of the gradient, but is likely confined to the high-resource islands of fertility (e.g., shrub understories) where exotic species can thrive (Brooks and Berry 2006).

In the high-disturbance end of the gradient, native richness increased in less fertile areas with large amounts of bare ground while exotic cover increased in fertile areas with less bare ground, suggesting that microscale differences may be providing refugia for native species. Habitat heterogeneity, namely, increased bare spaces, may be allowing native species to coexist with the exotic grasses and forbs at a particular site, although the native species found in the bare spaces may be different than those found under shrubs in the islands of fertility, which our study suggests may be prone to invasion. The same patterns regarding native species refugia have been observed in invaded grasslands on serpentine and non-serpentine soils (Harrison 1999; Gea-Izquierdo et al. 2007). Although habitat heterogeneity at the metacommunity scale has been shown to provide coexistence opportunities for native and exotic species, several studies have demonstrated increasing homogenization of native diversity by exotic species at larger scales (McKinney 2004; Qian and Ricklefs 2006), indicating that escape from extirpation may be temporary.

Patterns of native diversity across bio-physical gradients

The NMDS analysis revealed two distinct axes of diversity change, which nearly equally explained 
most of the variance observed in native diversity (87\%). The first axis was primarily correlated with precipitation and rockiness. Precipitation gradients are known to be strong drivers of species turnover (Kutiel et al. 2000; Pyke et al. 2001) and would be expected to be the primary driver in arid environments where water is limiting (Noy-Meir 1973). Rock cover can also influence species diversity by impacting soil moisture (Wood et al. 2005) and seed entrapment (Chambers 1995). As precipitation and rock cover may influence diversity through different mechanisms, and because of the correlation between precipitation and rock cover, it is difficult to separate out the effects of these two variables on patterns of native annual diversity.

The second diversity axis was correlated with elements of disturbance, namely, $\mathrm{N}$ deposition and wind. Dry season extractable $\mathrm{N}$ was also correlated with this axis and $\mathrm{N}$ deposition. The correlation between extractable and deposited $\mathrm{N}$ was expected due to the high proportion of dry-to-wet $\mathrm{N}$ deposition in arid and semi-arid environments, which leads to a buildup of $\mathrm{N}$ on the soil surface during the dry season (Padgett et al. 1999; Rao et al. 2009). The change in diversity patterns with $\mathrm{N}$ deposition and wind are likely linked with higher pressure from exotic species. Exotic species are promoted by wind and $\mathrm{N}$ enrichment (Lortie and Cushman 2007; Rao et al. 2009) and are known to suppress native species in this region (Barrows et al. 2009; Steers and Allen 2010). The relationship between exotic grass and forb cover with axis 2 is significant, but we are unable to determine from our analysis whether this is due to the direct influence of exotic species on native diversity, or that the exotic species in this region are promoted by disturbance, or some combination thereof.

Given that the NMDS indicated a relationship between exotic species and changes in native diversity, it was somewhat surprising that no evidence of homogenization was observed. Overall homogeneity was low and trended negative, indicating differentiation was occurring. Differentiation is observed when native and exotic species have similar geographic spread or when there are relatively few exotics compared to native species (Qian and Ricklefs 2006), such as occurred across our sites. In addition, homogenization may have been masked by the amount of winter-season precipitation that occurred during our sampling year, 2004-2005. Winter precipitation that season was unusually uniform throughout the entire landscape scale study area (Table 1) and 200-300 times the long-term average across the gradient. Multiyear data from the Indio Hills (north of Palm Springs) indicates that 2004-2005 precipitation elicited high native annual species richness (Steers 2008), which may have contributed to the lack of observed homogenization by exotics across our gradient. Of note, native annual species richness was even greater in the spring of 2008 than 2005 despite lower precipitation in 2007-2008 (Steers 2008). Thus, both sampling seasons appear to have been well suited for measuring native annual species richness across the respective spatial scales.

Geographical distance itself can also influence diversity patterns through physical limits on dispersal, speciation, and local extinctions, with the importance of geographical distance increasing with spatial scale (Nekola and White 1999). We found that distance was not correlated with diversity at our landscape scale $(85 \mathrm{~km})$ after controlling for the effects of precipitation and $\mathrm{N}$ deposition, which was likely due to the relatively small distance between the sites in comparison to the large ranges in average winter precipitation $\left(7.9-18.6 \mathrm{~cm}\right.$ winter $\left.{ }^{-1}\right)$ and $\mathrm{N}$ deposition (2.4-14.7 kg ha ${ }^{-1}$ year $^{-1}$ ). While there was no evidence of spatial structure on exotic forb cover, an effect of distance was observed on the exotic grass cover, but only after controlling for the $\mathrm{N}$ and precipitation gradients. Thus, some distance-based factors other than precipitation and $\mathrm{N}$ deposition, such as limitations in dispersal or wind, appear to be affecting the distribution of exotic grasses in this region. In coastal dune environments wind has been shown to be important in influencing soil texture, soil moisture, soil $\mathrm{N}$ patterns, and the dispersal of seeds, thus encouraging the invasion process through a variety of mechanisms (Lortie and Cushman 2007). In our study exotic grass cover is most positively correlated with windiness, followed by $\mathrm{N}$ deposition and rock cover, and the most parsimonious uncorrelated multiple regression model included wind as the primary explanatory variable (Table 2). The lack of a significant correlation of exotic grass cover with precipitation, and the fact that wind is significantly correlated with distance (Online Resource 1B), suggests that wind may be the component of distance influencing exotic grass cover in this region. 
This study demonstrates the importance of evaluating multiple anthropogenic and natural gradients when examining the factors that promote exotic species invasion and changes in native diversity. We found that exotic species in this region are promoted by large-scale disturbances, namely, $\mathrm{N}$ deposition and wind, although additional unmeasured biotic and abiotic factors are likely also affecting exotic species invasion and success. Despite the success of exotic species in areas with $\mathrm{N}$ enriched soil and high wind disturbance, native species also persist due, in part, to microsite heterogeneity. Homogenization of annual vegetation does not appear to be occurring across the gradient because there is high native richness, high turnover between sites, and relatively few exotic species, and because environmental factors associated with increased exotic plant abundance vary greatly across the gradient.

Acknowledgments This research was funded by the Community Foundation of Riverside and San Bernardino Counties, the National Park Service PMIS No. 72123, and the National Science Foundation DEB 04-21530. The manuscript was substantially improved by comments provided by C. Barrows and anonymous reviewers. Thanks also to Robert Johnson for GIS support and to the members of the E. Allen laboratory, especially Chris True, for field and lab support.

Open Access This article is distributed under the terms of the Creative Commons Attribution Noncommercial License which permits any noncommercial use, distribution, and reproduction in any medium, provided the original author(s) and source are credited.

\section{References}

Austin AT, Yahdjian L, Stark JM, Belnap J, Porporato A, Norton U, Ravetta DA, Schaeffer SM (2004) Water pulses and biogeochemical cycles in arid and semiarid ecosystems. Oecologia 141:221-235

Barrows CW, Allen EB, Brooks ML, Allen MF (2009) Effects of an invasive plant on a desert sand dune landscape. Biol Invasions 11:673-686

Beatley JC (1966) Ecological status of introduced brome grasses (Bromus spp.) in desert vegetation of southern Nevada. Ecology 47:548-554

Bonnet E, Peer YVd (2002) ZT: a software tool for simple and partial Mantel tests. J Stat Softw 7:1-12

Bowers JE (2005) El Nino and displays of spring-flowering annuals in the Mojave and Sonoran deserts. J Torrey Bot Soc 132:38-49
Brooks ML (2003) Effects of increased soil nitrogen on the dominance of alien annual plants in the Mojave Desert. J Appl Ecol 40:344-353

Brooks ML, Berry KH (2006) Dominance and environmental correlates of alien annual plants in the Mojave Desert, USA. J Arid Environ 67:100-124

CEC (California Energy Commission) (2007) California wind resources: annual wind speed map at 30 meter elevation. CEC Cartography Office, Sacramento

Chambers JC (1995) Relationships between seed fates and seedling establishment in an alpine ecosystem. Ecology 76:2124-2133

Davis MA, Grime JP, Thompson K (2000) Fluctuating resources in plant communities: a general theory of invasibility. J Ecol 88:528-534

DeFalco LA, Bryla DR, Smith-Longozo V, Nowak RS (2003) Are Mojave Desert annual species equal? Resource acquisition and allocation for the invasive grass Bromus madritensis subsp rubens (Poaceae) and two native species. Am J Bot 90:1045-1053

Fenn ME, Allen EB, Weiss SB, Jovan S, Geiser L, Tonnesen GS, Johnson RF, Rao LE, Gimeno BS, Yuan F, Meixner T, Bytnerowicz A (2010) Nitrogen critical loads and management alternatives for $\mathrm{N}$-impacted ecosystems in California. J Environ Manag 91:2404-2423

Gea-Izquierdo G, Gennet S, Bartolome JW (2007) Assessing plant-nutrient relationships in highly invaded Californian grasslands using non-normal probability distributions. Appl Veg Sci 10:343-350

Gutierrez JR, Meserve PL, Contreras LC, Vasquez H, Jaksic FM (1993) Spatial-distribution of soil nutrients and ephemeral plants underneath and outside the canopy of Porlieria-Chilensis shrubs (Zygophyllaceae) in arid coastal Chile. Oecologia 95:347-352

Harrison S (1999) Local and regional diversity in a patchy landscape: native, alien, and endemic herbs on serpentine. Ecology 80:70-80

Hobbs RJ, Huenneke LF (1992) Disturbance, diversity, and invasion: implications for conservation. Conserv Biol 6:324-337

Hooper DU, Johnson L (1999) Nitrogen limitation in dryland ecosystems: responses to geographical and temporal variation in precipitation. Biogeochemistry 46:247-293

Kutiel P, Kutiel H, Lavee H (2000) Vegetation response to possible scenarios of rainfall variations along a Mediterranean-extreme arid climatic transect. J Arid Environ 44:277-290

Lortie CJ, Cushman JH (2007) Effects of a directional abiotic gradient on plant community dynamics and invasion in a coastal dune system. J Ecol 95:468-481

McCune B, Medford MJ (1999) Multivariate analysis of ecological data. MJM Software, Glenenden Beach

McKinney ML (2004) Measuring floristic homogenization by non-native plants in North America. Glob Ecol Biogeogr 13:47-53

Motzkin G, Wilson P, Foster DR, Allen A (1999) Vegetation patterns in heterogeneous landscapes: the importance of history and environment. J Veg Sci 10:903-920

Nekola JC, White PS (1999) The distance decay of similarity in biogeography and ecology. J Biogeogr 26:867-878 
Noy-Meir I (1973) Desert ecosystems: environment and producers. Annu Rev Ecol Syst 4:25-51

NRCS (Natural Resources Conservation Service) (2006) Web Soil Survey. http://websoilsurvey.nrcs.usda.gov. Accessed 20 Mar 2006

Padgett PE, Allen EB, Bytnerowicz A, Minich RA (1999) Changes in soil inorganic nitrogen as related to atmospheric nitrogenous pollutants in southern California. Atmos Environ 33:769-781

PRISM (Parameter-elevation Regressions on Independent Slopes Model) (2006) United States average monthly or annual precipitation, 1971-2000. The PRISM Group at Oregon State University, Corvallis

Pugnaire FI, Haase P, Puigdefabregas J, Cueto M, Clark SC, Incoll LD (1996) Facilitation and succession under the canopy of a leguminous shrub, Retama sphaerocarpa, in a semi-arid environment in south-east Spain. Oikos 76:455-464

Pyke CR, Condit R, Aguilar S, Lao S (2001) Floristic composition across a climatic gradient in a neotropical lowland forest. J Veg Sci 12:553-566

Qian H, Ricklefs RE (2006) The role of exotic species in homogenizing the North American flora. Ecol Lett 9: 1293-1298

Rao LE, Allen EB (2010) Combined effects of precipitation and nitrogen deposition on native and invasive winter annual production in California deserts. Oecologia 162: 1035-1046

Rao LE, Parker DR, Bytnerowicz A, Allen EB (2009) Nitrogen mineralization across an atmospheric nitrogen deposition gradient in southern California deserts. J Arid Environ 73:920-930

Salo LF, McPherson GR, Williams DG (2005) Sonoran desert winter annuals affected by density of red brome and soil nitrogen. Am Midl Nat 153:95-109

Sawyer JO, Keeler-Wolf T, Evens JM (2009) A manual of California vegetation, 2nd edn. California Native Plant Society Press, Sacramento
Sharp RP (1964) Wind-driven sand in Coachella Valley, California. Geol Soc Am Bull 75:785-804

Shmida A, Whittaker RH (1981) Pattern and biological microsite effects in 2 shrub communities, southern California. Ecology 62:234-251

Steers RJ (2008) Invasive plants, fire succession, and restoration of creosote bush scrub in southern California. $\mathrm{PhD}$ Thesis, University of California, Riverside

Steers RJ, Allen EB (2010) Post-fire control of invasive plants promotes native recovery in a burned desert shrubland. Restor Ecol 18:334-343

Stohlgren TJ, Barnett DT, Simonson SE (2003) Beyond North American Weed Management Standards. North American Weed Management Association, Granby

Stohlgren TJ, Guenther DA, Evangelista PH, Alley N (2005) Patterns of plant species richness, rarity, endemism, and uniqueness in an arid landscape. Ecol Appl 15:715-725

Tieleman HW (1992) Wind characteristics in the surface layer over heterogeneous terrain. J Wind Eng Ind Aerodyn 41:329-340

Tonnesen GS, Wang Z, Omary M, Chien CJ (2007) Assessment of nitrogen deposition: modeling and habitat assessment. California Energy Commission, PIER Energy-Related Environmental Research. CEC-500-2006-032. http://www. energy.ca.gov/2006publications/CEC-500-2006-032/CEC500-2006-032.PDF. Accessed 10 June 2009

Wade JE, Hewson EW (1979) Trees as a local climatic wind indicator. J Appl Meteorol 18:1182-1187

Wood YA, Graham RC, Wells SG (2005) Surface control of desert pavement pedologic process and landscape function, Cima Volcanic field, Mojave Desert, California. Catena 59:205-230

WRCC (Western Regional Climate Center) (2010) Palm Springs, CA (043365) and Hayfield Reservoir, CA (043855). http:// www.wrcc.dri.edu. Accessed 2 Feb 2010 